\title{
RELAXAMENTO: UMA ESTRATÉGIA NO CONTEXTO DA ASSISTÊNCIA DE ENFERMAGEM
}

\section{RELAXATION, A STRATEGY IN THE CONTEXT OF NURSING CARE. \\ RELAJAMIENTO, UNA ESTRATEGIA EN EL CONTEXTO DE LA ASISTENCIA DE ENFERMERÍA}

\section{Maria Cícera dos Santos de Albuquerque ${ }^{1}$ Maria do Socorro Loureiro Cavalcanti ${ }^{2}$}

\begin{abstract}
RESUMO: Este trabalho realizou levantamento da aplicação do relaxamento como uma estratégia de assistência de enfermagem; visou, também, buscar um referencial teórico que subsidiasse a aplicação dessa técnica para atender às necessidades do cliente frente ao estado de doença, bem como servir de recurso a ser utilizado pelo enfermeiro no enfrentamento das situações estressantes. inerente à sua prática profissional. Trabalhamos os aspectos conceituais, a etimologia, a finalidade, a aplicação do relaxamento e sua implicação na assistência de enfermagem. Concluímos que a estratégia de relaxamento é uma habilidade que precisa ser aprendida e praticada, a fim de ser usada para aumentar o bem-estar. É uma modalidade terapêutica, não farmacológica, pode ser associada à terapêutica tradicional e de valor preventivo. Aumenta as opçōes de terapia eficaz para o enfermeiro. É uma técnica de "coping" em relação ao estresse, incorporá-la à prática de enfermagem exige que o enfermeiro perceba o cliente e a si mesmo como uma totalidade, ambos são beneficiados pelo uso desta estratégia.
\end{abstract}

UNITERMOS: Relaxamento - Estratégia - Assistência de enfermagem.

\begin{abstract}
This work has evaluated the application of relaxation as a strategy of nursing care; it has also sought for a theoretical framework that could base this technique application to assist the needs of a client facing his illness status, as well as a resource to be used by nurses in dealing with stressing situations, regarding to their professional praxis. We have worked upon conceptual aspects, the etimology, the aims, relaxation application and its implication in nursing care. We have concluded that relaxation technique is an ability that needs to be learned and praticesed in order to improve well-being. It is a therapeutic modality, not pharmacologic, can be associated to tradicional therapeutics and is of preventive value. It increases the options of efficcient therapy for nurses. It is a coping technique in relation to stress. For inserting it into nursing praxis it is demanding that the nurse perceive the client and himself as a whole for both are benefitted by this strategy use.
\end{abstract}

KEYWORDS: Relaxation - Strategy - Nursing care.

${ }^{1}$ Enfermeira. Prof ${ }^{\text {a }}$ Assistente III da Universidade Federal de Alagoas, Doutoranda em Enfermagem, no Programa de Enfermagem Fundamental, Escola de Enfermagem de Ribeirăo Preto, Universidade de São Paulo / USP.

2 Enfermeira. Prof ${ }^{2}$ Adjunto IV da Universidade Federal da Paraiba, Doutoranda em Enfermagem, no Programa de Enfermagem Fundamental, Escola de Enfermagem de Ribeirăo Preto, Universidade de São Paulo / USP.

R. Bras. Enferm. Brasilia, v. 51, n. 1, p. 35-52, jan./mar., 1998 
RESUMEN: Este trabajo realizó levantamiento de la aplicación del relajamiento como una estrategia de asistencia de enfermeria; viso, tambien, buscar un referencial teorico que subsidiase la aplicación de esa técnica para atender a las necesidades del cliente frente al estado de enfermedad, asi como servir de recurso a ser utilizado por el Enfermero en el enfrentamiento de las situaciones estresantes, inherente a su práctica profesional. Trabajamos los aspectos conceptuales, la etimologia, la finalidad, la aplicación del relajamento y su implicación en la asistencia de enfermeria. Concluimos que la estrategia de relajamiento es una habilidad que necesita ser aprendida y practicada, a fin de ser usada para aumentar el bienestar. Es una modalidad terapeutica, no farmacologica, puede ser asociada a la terapeutica tradicional y de valor preventivo. Aumenta las opciones de terapia eficaz para el enfermero. Es una técnica de "coping" en relación al stress; incorpọrarlo a la práctica de enfermeria exige que el enfermero perciba el cliente y a si mismo como una totalidad, ambos son beneficiados por el uso de esta estrategia.

UNITÉRMINOS: Relajamiento - Estrategia - Asistencia de enfermeria.

\section{INTRODUÇÃO}

Este trabalho abordará o tema relaxamento como uma estratégia no atendimento das necessidades do paciente e do enfermeiro, tomando por pressupostos três pontos elementares.

O primeiro é que a vida estressante tem acometido as pessoas do presente século, tendo em vista a exigência de sobrevivência que se caracteriza pela competição, falta de tempo, sobrecarga de atividades, na qual o ser humano é treinado para "estar pronto para tudo", desencadeando tensões excessivas nas pessoas. O segundo é que as pessoas têm se mostrado incapazes de enfrentar o aḍoecer. Na ocorrência de alguma doença, lidar com a dor, com as limitações geram tensões muito fortes. E o terceiro refere-se ao exercício da profissão de enfermagem permeada por uma constante exposição a situações de estresse decorrentes de dois aspectos: o primeiro é que, ao lidar com o cliente, o enfermeiro enfrenta no seu cotidiano a dor, a morte, o medo, a angústia, a tensão desses indivíduos, e para tanto necessita desenvolver habilidades para enfrentar tais situações; o segundo aspecto desta profissão é que a maioria de seus profissionais trabalha em hospitais, os quais exigem uma constante troca de turno, alterando o ritmo cicardiano desses profissionais ao inverter seus horários de trabalho, como também uma disponibilidade de renúncia aos fins de semana, feriados e festas comemorativas, o que compromete sua participação na vida familiar e social para atender aos seus clientes. Diante de tais aspectos surge uma necessidade, a de proporcioná-lhes uma maneira menos tensa de suportar tais estressores, e para isso o relaxamento pode ser uma das alternativas.

Para compreender a necessidade do relaxamento como estratégia faz-se necessário um trajeto na busca de entender o estresse. Na década de 70 , Madders (1978) já afirmava que "o estresse prolongado, seja devido a 
ansiedade, fadiga, ferimentos ou período de grande agitação, pode desencadear uma série de doenças. Algumas delas podem ser fatais e outras, embora não causem morte, muitas vezes arruinam a vida" (p. 11).

Segundo Madders (1978), Laura (1983), há uma relação muito estreita entre a tensão muscular e os estados emocionais, não há nada de anormal na tensão, na ansiedade ou na fadiga. Tudo isso faz parte de uma vida normal e ativa. É o que Auriol (1985) denomina de "eu estresse", ou seja o estresse positivo, favorável. Mas quando elas se tornam excessivas, prolongadas ou desnecessárias, ou seja, identificado por Auriol como estresse negativo desagradável, o nosso organismo reage em protesto. De acordo com Madders (1978), através do relaxamento se proporciona uma sensação de calma, redução da fadiga e afeta-se, em alguns pontos, o funcionamento do organismo fazendo com que a agitação desapareça.

Auriol (1985) distingue as reações ao estresse como reações musculares e reações do sistema nervoso vegetativo. As reações musculares podem ser de tensão, de preparação para (ataque ou fuga) ou, em um grau suplementar, de inibição da ação (pernas que amolecem, hipotonia). As pessoas tensas, segundo este autor, estão sempre de maxilares apertados, cabeça cravada nos ombros, costas retraídas, antebraços ligeiramente curvados, punhos quase cerrados.

“As vezes essa tensão muscular é menos aparente e é ao nível da pele que se revela tal vigilância, se tentarmos erguer a pele por um leve pinçamento desencadearemos uma dor freqüentemente muito forte" (p. 14).

Enquanto que as reações do sistema nervoso vegetativo são reconhecidas aos níveis do simpático e o do parassimpático.

Para este autor, o simpático facilita a atividade de defesa e ataque; o parassimpático reage por ocasião de um prazer. Afirma ele:

“O simpático estimulado excessivamente e sem que haja descontinuidade (combate ou fuga muscular) provoca o aparecimento de hipertensão arterial, enxaqueca, hipertireoidismo, distúrbios cardíacos, arteriosclerose, síncopes, diabetes, depressão. Enquanto que o sistema parassimpático, colite, asma" ( $p$. 15).

Auriol (1985), também ressalta que esse é o cortejo das doenças reconhecidas pela medicina contemporânea de "psicossomáticas".

Também afirma que na angústia ou ansiedade envolve-se de forma determinante as doenças da mente e do sentimento: neuroses, psicoses, distúrbios variados da personalidade. Existindo duas formas de angústia: a primeira é produzida pela incapacidade de manifestar a agressividade ou o medo; a segunda relaciona-se com a impossibilidade de se entregar ao prazer, encarado como perigoso ou culpado.

Auriol (1985) divide as causas do estresse como sendo por excesso ou por falta em diferentes níveis. 
- Físico - excesso ou falta de calor, excesso ou falta de ruído, de luz ...;

- Químico - excesso ou falta de calorias na ração alimentar, excesso ou falta de algum elemento químico determinado;

- Biológico - excesso ou falta de estimulações sensoriais;

- Psicológico - excesso ou falta de contatos afetivos;

- Sociológico e econômico - excesso ou falta de recursos, de atividade produtiva, de valorização pessoal;

- Gnosiológico - excesso ou falta de espiritualidade.

\section{EFEITOS DA TENSÃO NO ORGANISMO}

A tensão pode ter graves efeitos sobre o organismo, muitas vezes causando lesões nos órgãos e predispondo-os às doenças. É evidente que cada pessoa reage de uma maneira diferente à excitação e à tensão. $O$ corpo apresenta sinais e sintomas diferentes, de uma maneira peculiar em cada indivíduo, a depender da situação. Para Madders (1978) e Auriol (1985), todos temos o nosso tipo de reação indidual. Há pessoas que apresentam dores de cabeça numa situação de tensão, enquanto outras sofrem perturbações gástricas ou intestinais, pressão alta, urticária ou asma. Enfatizam que a reação ao estímulo é o resultado da entrada em ação do mecanismo de defesa do organismo diante de uma ameaça.

No momento em que é percebido o perigo, os músculos enrijecem e a mensagem é enviada ao cérebro. É o hipotálamo que comanda as emoções, coordenando harmoniosamente todos os sistemas encarregados de manter 0 equilíbrio interno necessário à sobrevivência.

Numa situação de intenso medo, um assalto por exemplo, numa fração de segundo, no cérebro desencadeia-se uma espantosa série de reações. Conforme Madders (1978), substâncias químicas são liberadas na corrente sangüínea, provocando alterações que preparam o organismo para entrar em ação, seja para lutar ou para fugir. Muitas dessas alterações ocorrem sem que 0 ser humano se dê conta delas, ou seja, tenha tempo de raciocinar. Desaparecendo o perigo, a emoção é descarregada, sobrevém o relaxamento e o organismo volta ao normal, segundo esta mesma autora, sem sofrer dano algum.

Madders (1978), Auriol (1985) e Gunther (1989) ressaltam, também, que o ser humano é capaz de ficar amedrontado ou excitado com algo que irá ocorrer no futuro ou quando se recorda de emoções que ocorreram no passado, tem a capacidade de provocar reações de alarme no seu organismo diante de fatos que ameaçam a sua auto-estima. Quando isso acontece, o organismo entra em ação, todas as alterações físicas e químicas são desencadeadas. Mantido esse estado por muito tempo, o homem acabará por se envenenar com suas próprias secreções. 
"Há provas, igualmente, de que se a tensão é muito prolongada o organismo se torna mais vulnerável às infecções" (p. 18).

Portanto, há dois caminhos para tal situação: ou muda-se do ambiente de tensão ou aprende-se a relaxar.

\section{RELAXAMENTO: ASPECTOS CONCEITUAIS}

Tentar definir o termo relaxamento não é uma tarefa simples tendo em vista o grau de popularidade que o mesmo adquiriu em nossos dias e o seu freqüente uso no vocabulário do público em geral. De acordo com Geissmann \& Bousingen (1987), há uma imensa confusão de linguagem e de expressão no uso da palavra relaxamento, levando a assumir inúmeros significados.

Segundo estes autores, o relaxamento é concebido por uma quantidade de pessoas ou grupos humanos como uma tentativa de se libertar física, moral, intelectual e afetivamente de uma coação. Esta coação seria um sentimento de mal-estar experimentado de forma cada vez mais grave pelos indivíduos ou grupos presos ao aspecto negativo da civilização do progresso em vias de organização.

Aspectos Históricos. Geissmann \& Bousingen (1987) afirmam que Sigmund Freud foi um dos primeiros, nos primórdios do século $\mathrm{XX}$, a prever a necessidade de certa libertação, tendo a idéia de estender o paciente sobre o divã, colocando o psicanalisado em repouso relaxante. O próprio psicanalista, também, assume uma posição confortável para atender convenientemente o paciente.

Em 1908, o professor Schultz (1939), tendo sido um dos alunos de Freud, idealizou o relaxamento como técnica terapêutica regulamentada, em paridade com a psicanálise, lançando tal idéia em público.

Geissmann; Bousingen (1987) ressaltam que, a partir dos estudos das regras do yoga e dos resultados obtidos por seus adeptos, foi que o Professor Schultz tirou os fundamentos da técnica e dos métodos de concentração, que se identificaram harmoniosamente com suas preocupações de psicanalista.

Entretanto, para Geissmann \& Bousingen (1987), tanto a técnica psicanalítica, de um lado, quanto o método de Schultz, de outro, apresentaram suas próprias regras e projetos aparentemente opostos, o que propiciou 0 desenvolvimento perfeitamente independente das duas técnicas, embora fossem ambas utilizadas por neuropsiquiatras que nelas reconheciam notáveis instrumentos de trabalho.

Vários autores, conforme Geissmann \& Bousingen (1987), partiram de uma posição de psicoterapeutas, de neurofisiologistas ou de especialistas da rítmica e descobriram paralelamente o papel máximo do relaxamento na terapêutica e 
na profilaxia dos distúrbios neuróticos do século $X X$, permitindo a origem de uma variedade de métodos de relaxamento.

Definição e Sentido Etimológico. Para uma compreensão mais adequada do termo relaxamento, faz-se necessário uma incursão no seu âmbito etimológico, tanto da origem quanto no sentido da palavra.

No latim, o vocábulo relaxatio apresenta o sentido de relaxar, como também o de soltura de um prisioneiro, bem como o de descanso, repouso. Já no século $\checkmark$ a.C., relaxator é o remédio relaxante na compreensão médica; relaxar é usado na antigüidade tendo um sentido fisiológico ou médico.

$\mathrm{Na}$ linguagem grega, o verbo relaxar significa alongar, estender.

Para o dicionarista Robert (1964), apud Geissmann; Bousingen (1987), o relaxamento faz parte dos métodos psicossomáticos.

“Os métodos relaxantes são processos terapêuticos bem definidos, visando a obtenção de uma 'descontração muscular e psíquica' no indivíduo, por meio de exercícios apropriados; a descontração neuro-muscular resulta num 'tono de repouso', base de uma distensão física e psíquica. O relaxamento destarte é uma técnica de busca de repouso mais eficaz possível, ao mesmo tempo que a busca da poupança das forças nervosas utilizadas pela atividade geral do indivíduo" (p.11).

No que corresponde à sua definição, para Auriol (1985), relaxamento é o que se opõe ao estresse, o que reforça a homeostase, o que diminui a angústia e a emotividade e o que proporciona a verificação dos elementos do organismo.

Entretanto, segundo Dossey (1992), o relaxamento é um estado psicofisiológico, caracterizado pelo domínio do parassimpático e que é seguido por estratégias específicas para estimular a resposta de relaxamento. A resposta de relaxamento é um estado de alerta hipometabólico de diminuição do estímulo do sistema nervoso simpático, no qual a pessoa sente uma sensação de calma.

Pelletier (1979), Apud Herman (1985), também vê o relaxamento como um estado em que o sistema nervoso simpático é inibido: o indivíduo apresenta uma diminuição no consumo de oxigênio, na freqüência do pulso, na pressão arterial, na taxa da respiração e no tônus muscular - esquelético. A característica psicológica mais importante é uma diminuição da ansiedade.

\section{RELAXAR PARA QUE?}

1. Como uma arma contra o estresse. Madders (1978) apresenta o estresse com um significado amplo; segundo a sua óticr 'ais que a ansiedade e tensão simplesmente. Pode signitıcar também superexcitação de qualquer outra coisa que o nosso organismo interprete como ameaçadora. Neste campo, ela inclui coisas muito variadas, tais como barulho, críticas e mudanças drásticas no modo de vida das pessoas, como, por exemplo, uma patologia. Segundo esta 
autora não é a situação em si que causa mal, e sim a nossa reação a ela. $\mathrm{E}$ é isso que o relaxamento ajuda a controlar. Sua experiência lhe permite afirmar que, quando 0 indivíduo consegue relaxar voluntariamente, os músculos sentem também uma sensação de relaxamento muscular e a tranqüilidade da mente.

2. No combate à fadiga. De acordo com Madders (1978), as pessoas, geralmente, não se dão conta das desnecessárias tensões musculares a que são submetidas na vida cotidiana, e isso resulta em fadiga. Portanto, os exercícios de relaxamento são indicados para tais tensões.

3. Ajudando a enfrentar a dor. Para Madders (1987),

"o relaxamento faz com que a dor doa menos, ao passo que a tensão faz com que ela aumente" (p. 14).

Afirma que o relaxamento na cadeira do dentista torna o tratamento mais suportável, tanto para o cliente como para o dentista. Pode ser aplicado em qualquer situação em que haja expectativa da dor ou quando é inevitável. Ressalta que sua aplicação durante o parto vem sendo feita há muitos anos.

4. Melhorando o desempenho das atividades físicas. Madders (1978) afirma que as tensões desnecessárias prejudicam o bom desempenho das atividades no trabalho, no esporte. A tensão muscular poderá fazer a diferença entre um esplêndido desempenho e uma apresentação inteiramente medíocre.

5. Auxiliando no relacionamento com os outros. As pessoas simpatizam com quem se mostra calmo e relaxado. Se você estiver tranqüilo, verá que saberá enfrentar situações difíceis com paciência, sem se irritar. Quando o seu corpo está relaxado, a sua voz e as suas maneiras influem nas pessoas que o cercam, ajudando-as a diminuir a própria tensão. Mas no momento em que se tornar necessário você mostrar firmeza e energia, isso será feito com resultados positivos, e a calma positiva Ihe voltará em seguida, sem maiores conseqüências.

\section{RELAXAMENTO: IMPLICAÇÕES NA ASSISTÊNCIA DE ENFERMAGEM}

É importante que o enfermeiro desenvolva a habilidade de observar e identificar o estado de estresse de seus pacientes; para ajudá-los de forma mais eficaz, deverá estar atento as situações psicológicas, fisiológicas e sociais estressantes. Deve considerar que a dor, a ameaça, a vergonha e a culpa interferem na habilidade de enfrentamento do indivíduo.

Dossey (1992) considera que a ansiedade, as questões de vida e de morte são experiências complexas para qualquer paciente. Um corpo de conhecimento rapidamente crescente apoia que há uma ligação entre as emoções e as doenças e aponta as maneiras de enfrentá-las, afastando-se de um modelo 
mecanicista puramente baseado em como o ser humano funciona, mas admite que a mente pode desempenhar um papel negativo como também tem um potencial para afetar a saúde, a doença e a cura de uma maneira positiva e poderosa.

Segundo King (1981), alguns estudos de enfermagem têm identificado alguns estressores na hospitalização, na doença e no ambiente de trabalho. Rigorosos estudos propõem formas pelas quais o enfermeiro pode identificar 0 estresse, podendo prover cuidados de enfermagem que ajudem os pacientes a lidar com o estresse da doença. King (1981) afirma que pacientes que receberam informação, que participaram no plano de ensino no pós-operatório e expressaram seus sentimentos sobre a cirurgia apresentaram uma diminuição da tensão.

Smith \& Selye (1979) dizem que o primeiro papel do enfermeiro, ao assistir o indivíduo em qualquer estágio de estresse, é: aconselhar e ensinar como estar à altura de produzir uma maneira positiva de enfrentar o estresse; * assistir o indivíduo na adaptação à doença através de habilidades técnicas, cuidado e suporte emocional; e *ajudar as famílias dos indivíduos, de acordo com o desequilíbrio causado por sua doença e hospitalização.

Estas autoras sugerem que estes três aspectos são fundamentais para reduzir os efeitos negativos do estresse. Portanto, o enfermeiro deve considerar que as pesquisas têm mostrado que é possível orientar o cuidado de saúde em direção à prevenção do estresse, manutenção da saúde e, até certo ponto, correção das patologias existentes; e para satisfazer este papel adequadamente deve estar hábil para: compreender o conceito do estresse; conhecer quais fatores alteram a resistência ao estresse; formular realisticamente planos para fortalecer estes condicionantes positivos; implementar ações para reduzir o estresse do indivíduo; e educar os indivíduos a respeito de como controlar seus próprios estressores.

King (1981) sugere que, quando não há possibilidade de evitar as situações ou ambiente causadores de estresse, se deve utilizar alguma forma para enfrentá-los. Segundo esta autora, o relaxamento é uma técnica que vem sendo utilizada como uma forma de ajudar a reduzir tensão no enfrentamento do estresse pelo paciente e profissionais de enfermagem.

Pesquisa de Relaxamento na Enfermagem. O uso do relaxamento na assistência de enfermagem vem sendo observado desde a década de 70 nos trabalhos publicados de Aiken \& Henrichs (1971); Aiken (1972), com o objetivo de usar a técnica de relaxamento com pacientes submetidos a cirurgias cardíacas, na redução do estresse no pré-operatório, como também no pósoperatório. Ou seja, prevenção de psicoses após cirurgias cardíacas. As autoras constataram que tais pacientes apresentaram menos complicações psiquiátricas no pós-operatório.

Breeden \& Kondo (1975) utilizaram o relaxamento através do "training biofeedback" para reduzir a ansiedade de pacientes psiquiátricos e reduzir 
sintomas psicossomáticos. Foi observado, por estas autoras, que houve diminuição nos níveis de ansiedade e uso de medicamentos psicotrópicos, como também adaptação maior desses pacientes ao seu ciclo social.

Stwart (1976) sugere o uso do relaxamento, combinado com a respiração em ritmo regular, como intervenção de enfermagem para encorajar os pacientes no "coping" da dor, como também na sua diminuição.

Flaherty \& Fitzpatric (1978) apresentam um estudo preliminar a respeito da técnica de relaxamento para aumentar o nível de conforto dos pacientes no pósoperatório. O estudo foi realizado com 42 pacientes, com idade entre 18 e 65 anos, hospitalizados para cirurgias eletivas. Os pacientes foram divididos em dois grupos iguais e eqüitativamente distribuídos os de colecistectomia, herniorrafia e hemorróidectomia: o grupo no qual foi aplicada a técnica de relaxamento e o grupo controle no qual foi aplicado a técnica de relaxamento. As autoras concluíram, que o grupo no qual foi aplicado a técnica de relaxamento apresentaram menos dor na incisão, usaram menos analgésico, aumento do nível de conforto nas primeiras 24 horas de pós-operatório e menos dificuldade para levantar-se.

Ressaltamos que na década de 80 surgem vários trabalhos na enfermagem, dos quais mencionaremos os de Hennington (1983), Lamontagne; Mason \& Hepworth (1985), Holden-Lund (1988), e Titlebaum (1988) por ordem cronológica.

Hennington (1983) explora o conceito de relaxamento e suas implicações para a enfermagem. Para ela, ambos, enfermeiro e seus clientes são beneficiados com o processo de relaxamento. Ressalta que nos livros textos de enfermagem são incluídas técnicas de relaxamentos nos capítulos destinados ao estresse.

De acordo com Hennington (1983), o uso da técnica de relaxamento é um novo desafio para a assistência de enfermagem, a ser efetivada para todos os pacientes e em toda espécie de tratamento. É desafiador, como aponta Dossey (1992), para a enfermagem auxiliar o cliente a compreender que o corpo e a mente são conectados e que a terapia da mente, usada em conjunção com terapias médicas, pode intensificar o processo de cura.

Segundo esta autora, o relaxamento não é uma nova habilidade para enfermeiros e clientes, entretanto, é uma habilidade que precisa ser reaprendida e praticada a fim de ser usada com sucesso para aumentar o bem-estar.

Lamontagne; Mason \& Hepworth (1985) apresentam o efeito do relaxamento em crianças de 7 anos, com ansiedade em sala de aula, com implicações para beneficiar o "coping" ao estresse. Para as autoras, a estratégia de relaxamento pode ser usada em crianças para encontrar o controle do seu estresse e que os resultados mostraram uma diminuição da ansiedade naquelas que vivenciaram o relaxamento. O treino do relaxamento foi adaptado para crianças e realizado por condução da associação de imagem; utilizando estórias infantis, era sugerido a elas que se imaginassem como o personagem. 
Programas de reeducação de estresse em escolas tem sido utilizado para ajudar as crianças nos seus conflitos, na sua promoção de saúde e no ajustamento.

Holden-Lund (1988) também apresenta o resultado do uso do relaxamento no pré-operatório de 24 pacientes, submetidos a colecistectomia, através da condução à associação de imagem, concluindo que o grupo apresentou, significativamente, menos estado de ansiedade, menor nivel de cortisol no primeiro dia de pós-operatório e menos evidência de eritema na ferida cirúrgica.

$\mathrm{Na}$ década de 90 , na prática dos enfermeiros americanos, o relaxamento se apresenta essencialmente através do uso da condução à associação de imagem: seus efeitos produzindo diminuição da ansiedade em pacientes submetidos à ressonância magnética, no trabalho de Thompson \& Coppens (1992); em pacientes com dispnéia e doenças pulmonares obstrutivas crônicas, levando à diminuição da ansiedade, do ritmo respiratório, da dispnéia e do espasmo brônquico, verificado na pesquisa de Gift; Moore; Soeken (1992); no atendimento a primiparas, objetivou ajudá-las a enfrentar a ansiedade, depressão, baixa auto-estima durante a gravidez e o pós-parto, nas pesquisas de Rees (1992), Rees (1993), Rees (1995).

O Relaxamento e os Profissionais da Enfermagem. Uma preocupação por parte do profissionais de enfermagem atualmente é: como realizar o cuidado e ao mesmo tempo uma qualidade de cuidado durante as atividades com pacientes por longo periodo de tempo, freqüentemente sob condições de estresse?

Na perspectiva de King (1991), os estudos têm mostrado que a rotação dos turnos, altera o ritmo circadiano dos enfermeiros e pessoal da enfermagem, causando fadiga e reduzindo a eficiência no trabalho.

Henningthon (1983) afirma que estudantes de enfermagem e enfermeiros, submetidos a uma variedade de situação de estresse, desfrutando do relaxamento, poderão se beneficiar-se com a promessa de uma vida longa. $O$ treinamento do relaxamento é uma positiva ponte entre o foco da doença e a própria responsabilidade com a saúde. Benefícios são freqüentemente aparentes, os quais trazem positivos reforços, principalmente quando a técnica é adequada. Além disso, enfermeiro e clientes estão compartilhando uma experiência de prazer, a qual promove um relacionamento positivo na assistência.

As instituições que prestam assistência à saúde deveriam ter uma preocupação em fornecer atividades de relaxamento, principalmente para os profissionais que lidam diretamente com o paciente, mais especificamente os enfermeiros, para aumentar seu autocontrole, ganho de agilidade mental, sustentar o próprio mecanismo de "coping" , assim como fornecer uma ferramenta de trabalho. 
Benefícios do Relaxamento. Vale ressaliar que o relaxamento responde, na visão de Henningthon (1983), como uma modalidade não farmacológica, considerado como terapêutico, como também de valor preventivo para muitos indivíduos que convivem com situaçōes em que estão presentes excessivas situações do sistema nervoso simpático e fatos indesejáveis, inesperados e desagradáveis. Na concepção de Dossey (1992), o relaxamento é uma técnica de "coping" em relação ao estresse, e incorporar essa técnica na prática da enfermagem exige que o enfermeiro perceba o paciente como uma totalidade.

Kolkmeier (1980) ressalta que o treinamento do relaxamento traz benefícios, como: diminuição da ansiedade associada a situações dolorosas (ex. troca de curativos); da dor na tensão muscular de contrações dos músculos esqueléticos; da fadiga acessando a resposta de luta ou fuga; proporciona um período de descanso benéfico, como o cochilo que ajuda o indivíduo a dormir rapidamente; aumenta os efeitos das medicaçőes para dor; ajuda o indivíduo a se dissociar da dor.

A técnica de relaxamento a ser aplicada fica a critério do enfermeiro, mas isto vai depender do seu conhecimento e da sua familiaridade com as diversas técnicas e, principalmente, das condiçб̋es, necessidades, preferéncias pessoais e tempo disponivel do cliente.

Incorporar técnicas de relaxamento à prática, na sugestão de Dossey (1992), fornece ao enfermeiro intervençőes necessárias para cuidar do cliente como um todo. Tais técnicas de auto-regulaçăo aumentam as opçőes de terapia eficaz pelo enfermeiro e podem produzir resultados tão reais como aqueles produzidos pelas formas tradicionais de terapia. Terapias holísticas de auto-regulação săo usadas para tratar a ansiedade, estresse e dor inerentes às doenças do corpo de forma aguda ou crônica. Elas são usadas para estabelecer um senso de balanço e controle do estado emocional da pessoa, o que por sua vez afeta diretamente o estado fisiológico.

Dossey (1992), também afirma que freqüentemente os pacientes não sabem como ativar o potencial para a cura que eles têm em seu próprio "corpo-menteespírito". Os enfermeiros têm, entretanto, a habilidade de auxiliar aos pacientes a ativar este processo; o desafio é auxiliá-los a compreender que o corpo e a mente são conectados e que a terapia da mente, usada conjuntamente com as terapias médicas tradicionais, pode intensificar o processo de cura.

Henningthon (1983) sugere que a técnica de relaxamento seja praticada nas seguintes situaçóes: antes das cirurgias ou outros procedimentos que provoquem ansiedade no cliente; em doenças crônicas, tais como as doenças crônicas obstrutivas pulmonares; na reabilitação de pacientes com infarto; nas cefaléias e tensão muscular crônicas; na hipertensăo; durante o labor e na ansiedade.

Entretanto, para Titlebaum (1988), a técnica de relaxamento deverá ser adotada quando o objetivo do enfermeiro, com a assistência de enfermagem, for: reduzir a tensão; reduzir antecipadamente a ansiedade; reduzir a ansiedade em 
resposta ao estresse; aumentar a atividade parassimpática; aumentar a consciência da tensão muscular e estímulo automático; aumentar a concentraçăo; aumentar o senso de controle; aumentar a habilidade que impede o diálogo interior; energizar; promover o sono; aumentar a sugestão; diminuição do ritmo cardíaco; diminuiçăo da pressão sangüínea; redução da dor e percepção da dor e redução de partes quentes ou fria do corpo.

Titlebaum (1988) diz que a terapêutica do relaxamento, na enfermagem, tem sido dirigida em várias situaçőes: da promoção de saúde aos problemas de doença, com variado grau de sucesso. Tal afirmação decorre dos exemplos de experimentos clínicos e estudos oriundos da literatura da enfermagem. Existem relevância na prática de enfermagem e uma gama de potencial nesta área para futuros estudos.

O enfermeiro lida, diariamente, com o medo e a dor dos clientes. Titlebaum (1988) sugere que a dor pode ser parcialmente o resultado da resposta ao sofrimento (isto é perceptivel através da ansiedade, tensão muscular, respiração contida, gritos); através da técnica de relaxamento, o enfermeiro poderá levar o pacientes a diminuir o seu estado de estresse, enfrentar a dor e o medo de uma forma menos traumática, menos angustiante.

Henningthon (1983) afirma que o relaxamento não é apenas uma excelente técnica para redução do estresse e promoção da saúde, ele é um método que beneficia o enfermeiro assim como o paciente. Ao mesmo tempo que ensina ao paciente para relaxar, o enfermeiro reduzirá o estresse da sua vida com a sua atividade de trabalho e promove o seu próprio senso de bem-estar.

Ao enfermeiro que busca utilizar o relaxamento como estratégia no cuidado do cliente cabe considerar: o início e manutenção de uma relação de ajuda; a eleição, entre as diferentes técnicas, da mais adequada às necessidades do cliente, no momento; que, através do relaxamento, se elabora uma alteração progressiva: "de ter um corpo" ou de "ter uma doença" evolui para ser um "corpo tornando-se bom"; a formulação para o paciente de uma "intenção proposta" que agirá como um modelo analógico, mobilizando globalmente as estruturas inconscientes e conscientes do cliente; que a palavra do enfermeiro deve ser profundamente aceita pela paciente, de forma acalentadora; a necessidade da aprendizagem pessoal da técnica do relaxamento depende do caráter peculiar experimental e do alcance da técnica, sob a direção do profissional experimentado, até que tenha adquirido perfeito controle; que haverá grande progresso terapéutico quando o paciente com desordem orgânica for compreendido pelos profissionais de doenças orgânicas, como parcial ou totalmente psicossomáticas; que um grande número de pacientes se beneficiarão com o uso do relaxamento.

\section{PROCESSO DE ENFERMAGEM}

Para utilizar o relaxamento como intervenção, é importante levantar e considerar as seguintes informaçőes, na percepçăo de Kolkmeier (1983): 
percepçăo pessoal do cliente do nivel de tensão e necessidade do relaxamento; prontidăo e motivação do cliente para aprender a estratégia de relaxamento; por ser o relaxamento muito subjetivo e de esforço pessoal, o paciente pode estar preparado e entusiasmado para participar; experiências passadas do cliente com o processo de relaxamento, hipnose ou meditaçăo, extrair as definiçōes do cliente e qual o seu significado pessoal de relaxamento; perspicácia em ouvir o cliente para poder falar em nível apropriado ao guiá-lo nos exercícios de relaxamento; identificar a crença religiosa do cliente afim de que possa apresentar um meio confortável e compativel com o sistema de crença do paciente; habilidade do cliente para permanecer em uma posição confortável por 15 a 30 minutos; o nível de dor e desconforto, ansiedade, medo ou tédio do paciente; a percepção da realidade do cliente, história de estado de despersonalização, e "locus" de controle; indivíduos pré-psicóticos e psicóticos podem experimentar uma exacerbação dos sintomas quando aprofundam o relaxamento; quantidade de medicação usada pelo paciente, enfocando os medicamentos que podem alterar as respostas para o relaxamento, ou quando necessitará ser alterada com o progresso do relaxamento; estar particularmente alerta para a necessidade de modificação da dosagem de insulina, medicações anti-hipertensivas, pílulas para dormir, tranqüilizantes e antidepressivos.

Diagnósticos de Enfermagem. Kolkmeier (1988) aplica o relaxamento aos seguintes diagnósticos de enfermagem, inseridos nos nove padrōes de respostas humanas:

\begin{tabular}{|c|c|}
\hline RELACIONAR: & Isolamento social. \\
\hline VALORIZAR: & Estresse espiritual. \\
\hline ESCOLHER: & $\begin{array}{l}\text { "Coping" ineficaz (individual e familiar), ajustamento ineficaz, não } \\
\text { aderência, negação ineficaz, conflito de decisão. }\end{array}$ \\
\hline MOVER: & $\begin{array}{l}\text { Intolerância à atividade (real ou potencial), déficit de atividade } \\
\text { diversional, distúrbio no padrăo do sono, fadiga. }\end{array}$ \\
\hline PERCEBER: & $\begin{array}{l}\text { Distúrbio da auto-estima e do autoconceito, falta de esperança, } \\
\text { preturbaçăo no desempenho de papel e de identidade pessoal, } \\
\text { falta de poder (impotência), alteração no senso de percepção } \\
\text { (visual, auditiva, cinestésica, gustativa, tátil, olfativa). }\end{array}$ \\
\hline CONHECER: & Processo de pensamneto alterado, déficit de conhecimento. \\
\hline SENTIR: & $\begin{array}{l}\text { Ansiedade, luto, alteração no conforto (dor, medo), potencial para } \\
\text { violência (autodirigido ou dirigido aos outros.) }\end{array}$ \\
\hline
\end{tabular}

A estratégia de relaxamento pode ser utilizada nas situaçőes diagnósticas que envolvam dor, perdas, medo, ansiedade, tensão, emoções perturbadas; também é indicada, quando se busca melhorar as funçőes orgânicas que se encontram em padrões alterados. Salientamos que é importante considerar a capacidade psicomotora e de envolvimento do cliente.

Kolkmeier (1988) sustenta que não importa a abordagem preferida quando se quer utilizar o relaxamento como estratégia de autocuidado, visto que o resultado final é um movimento das pessoas em direção ao equilíbrio e à cura. 
Planejamento. Kolkmeier (1988) sugere o planejamento dirigido ao resultado do cliente, exemplificando da seguinte forma: 1) meta: o cliente deverá apresentar diminuição da ansiedade, tensăo e outras manifestaçర̋es de resposta ao estresse como resultado da intervençăo do relaxamento. 2) objetivos: o cliente deverá exibir decréscimo da ansiedade, tensăo, e outras manifestaçőes de resposta ao estresse evidenciado por: a) freqüência cardiaca nos limites normais; b) diminuiçăo da frequeência respiratória; c) resoluçăo do comportamento ansioso, tais como expressão facial ansiosa e maneirismo, falas repetidas ou incapacidade para dormir, ou ansiedade expressa.

Avaliação: o cliente exibiu decréscimo da ansiedade, tensão e outras manifestaçőes de resposta ao estresse evidenciado por sinais vitais normais, respiração profunda e lenta, diminuição do comportamento ansioso.

- Antes da sessão de relaxamento é importante considerar: o uso da técnica de relaxamento aproxima paciente e enfermeiro; o paciente deve ser encorajado a praticar o relaxamento; rever com o cliente ou colher informaçăo no prontuário, com outros profissionais da equipe, concernente a dor, ansiedade, e níveis depois da sessão; reservar um tempo de 15 ou 45 minutos ininterruptos; fechar a porta para diminuir barulhos e distraçőes; desligar o telefone, deixando alguém responsável para atendê-lo; reduzir o nível de iluminação; verificar se o paciente esvaziou a bexiga antes do início do relaxamento; auxiliar o paciente para encontrar uma posição confortável; evitar realizar o relaxamento antes da refeição ou até 2 horas depois da última refeição, pois um estômago cheio junto com o relaxamento pode levar ao sono; ter todo o material disponivel em mãos, tais como: tape, cobertor, travesseiro; se a sessão for seguida de desenho, ter papel e lápis para fazer a avaliação.

- No começo da sessão: escolher a técnica de relaxamento em conformidade com o paciente e de acordo com as suas necessidades; rever rapidamente os beneficios da experiência para o paciente e sua cooperação; expor ao paciente que o relaxamento pode ser facilitado se praticado com os olhos fechados; verificar os sinais vitais do paciente; explicar que guiará a respiração e os exercícios do paciente; explicar que o resultado do relaxamento depende do envolvimento, interesse e prática do paciente; definir com o paciente os objetivos da sessão: redução da dor, diminuiçăo do tempo para dormir, reduçăo da ansiedade, etc..

- Durante a Sessão: observar a resistência e/ou envolvimento do cliente na técnica de relaxamento; a velocidade, 0 uso de frases de sugestăo depende da técnica de relaxamento escolhida.

- Após o relaxamento: trazer o paciente gradualmente para o estado de acordado, re-energizando, movimentando as mãos e espreguiçando-se; verificar os dados vitais do paciente; discutir com o paciente a respeito da experiência; encorajar o paciente a continuar a praticar os exercícios; rever os sintomas; fazer as anotaçőes pertinentes no prontuário do paciente. 
Implementação. A implementaçăo é orientada para a meta. As ações consistem nas finalidade e resultados esperados do plano. Quando o enfermeiro realiza açőes habilidosas e eficientemente, a confiança do cliente na competência do enfermeiro é aumentada, melhorando a relaçăo enfermeiropaciente.

A seguir, descreveremos dois métodos de utilizaçăo da estratégia relaxamento, segundo aponta Kolkmeier. (1988):

- Consciência da Tensão Através do Relaxamento Muscular Progressivo

Finalidade: Ajudar o paciente a identificar níveis sutis de tensăo mental, ansiedade e a tensão física que o acompanha, com tempo de duraçăo entre 10 e 20 minutos.

Roteiro: Primeiro leve alguns momentos para enfocar sua expiraçăo. Isto o ajudará a enfocar melhor pistas internas de tensăo muscular $\Theta$ entăo relaxamento. Eu dirigirei vocé quando começar a se mover através de seus músculos em seu corpo. Torne-se consciente de como pode ganhar controle sobre a tensão encontrada nesses músculos. Este processo envolve alternadamente estiramento e relaxamento de grupos musculares. Deixe vocé estirar cada grupo de músculos, segure a tensão durante 5 a 10 segundos, após o que leve fadiga será sentida na área, e entăo libere a tensăo ... Comece com os músculos de seus pés e pernas, enrijeça essa área tanto quanto puder. Puxe seus artelhos para cima, em direçăo à cabeça, e se conscientize de que os músculos enrijecem e que você continua a segurar essas rigidez, eles talvez tremam ou se sacudam um pouco quando se cansarem... Agora, deixe a tensăo lentamente se dissolver e sinta a diferença nas suas pernas e pés... Deixe a sua atençăo voltar-se para seus joelhos e coxas; tensione esses músculos pressionando suas pernas na superficie da cama (sofa, assoalho ou cadeira)... Quando você estiver consciente de como eles se sentem, entăo permita que a tensão fuja quando você expirar.

Proceda para as seguintes áreas: quadris e nádegas; abdome e região lombar; tórax anterior e posterior; ombros e bíceps; antebraços e måos; pescoço e ombros; mandíbula e lingua; $\Theta$, finalmente, músculos faciais. Deve-se observar se há relato de dor ou dificuldade com uma certa parte do corpo, começando o exercício tăo longe da área envolvida quanto possível. Conclua o exercício com a área primária de dificuldade.

Quando o cliente se torna consciente da diferença interma induzida por este processo, ele pode mover-se para níveis limiares de tensăo, segurando suficiente rigidez no grupo muscular para estar consciente da tensăo inicial e entăo relaxando o grupo. Movendo de contrações fortes para contraçర̋es sutis, o cliente se torna consciente da habilidade de sintonizar o processo de relaxamento. 
O cliente deve estar acomodado para respirar através da sessăo, portanto evitando a tentaçăo de segurar a respiraçăo quando se enrijecem. A tensão nos músculos deve ser mantida livre de desconforto.

O relaxamento muscular progressivo é particularmente efetivo para clientes que estáo se sentindo fisicamente tensos, ansiosos e talvez agitados. Porque é um intervençăo ativa, pode ser preferida em relaçăo a exercícios passivos, especialmente no início do treinamento do cliente. Entretanto, deve ser usado com cuidado em pacientes com hipertensăo e com dor nas costas.

\section{- Volta ao equilíbrio através do Treinamento Autógeno}

Finalidade: Ajudar a reequilibrar conscientemente os mecanismos homeostáticos internos dos sistemas cardiovascular e respiratório, que simultaneamente afetam os sistemas autônomo, endócrino, imunológico e neuropeptídeo; por um tempo variável entre 10 a 20 minutos.

Roteiro: Lenta e silenciosamente, repita as seguintes frases a si mesmo quando eu disser para você (repita cada frase 2 a 4 vezes, fazendo uma pausa de alguns segundos entre as respiraçăo): Estou começando a me sentir muito quieto... Estou começando a me sentir muito relaxado... Meus pés, joelhos e quadris se sentem pesados... Peso e calor estão fluindo através dos meus pés e pernas... Minhas mãos, braços e ombros sentem-se pesados... Calor e peso estão fluindo através das minhas măos e braços... Meu pescoço, mandíbula, língua e fronte se sentem relaxados e suaves... Todo o meu corpo se sente quieto, pesado e confortável... Estou confortavelmente relaxado... Calor e peso fluem nos meus braços, mãos e dedos... Minha respiração é lenta e regular... Estou consciente do meu batimento cardiaco calmo e regular... Minha mente está se tornando mais quieta quando eu enfoco para dentro... Profundamente na mente, experimento-me relaxado, confortável e parado... Estou alerta de uma forma quieta e interior... Quando termino meu relaxamento, faço várias respiraçōes profundas, reernegizantes, trazendo luz e energia a cada célula do meu corpo.

Avaliaçăo. Segundo Christensen; Kenney (1995), a avaliaçăo pode ser conceitualizada de três formas: de estrutura (enfoque no equipamento físico); de processo (enfoque nas atividades do enfermeiro) e de resultados (enfoca alteraçōes no comportamento do cliente e estado de saúde). Na aplicação da estratégia de relaxamento, espera-se que haja uma alteração no estado de saúde do cliente e seu comportamento.

\section{CONSIDERAÇŎES FINAIS}

Pautadas na realizaçăo deste estudo, afirmamos que o relaxamento é um instrumento importante para ser utilizado tanto na assistência de enfermagem quanto na perspectiva do alivio das tensöes causadas aos enfermeiros e à sua equipe, decorrentes das situações estressantes específicas da profissăo. 
Cabe também considerar que o uso dos variados métodos de relaxamento fica a critério do enfermeiro, da sua competência para utilizá-los e da sua sensibilidade em adaptar o método às necessidades do paciente.

O uso adequado da estratégia de relaxamento está estreitamente relacionado com a habilidade do enfermeiro de observar e identificar o estado de estresse de seu cliente, ao considerar questões, tais como: dor, ameaça à vida e morte, como situações que promovem intenso estresse.

É importante que, ao identificar tais situaçōes, o enfermeiro proponha cuidados de enfermagem que ajudem o paciente a lidar com o estresse da doença, que o assista na adaptação à hospitalização e/ou doença e que ajude a família do paciente a lidar com o desequilibrio da doença e da hospitalização.

Ressaltamos, também, que as pesquisas norte-americanas, desde a década de 70 , vêm mostrando o benefício da estratégia de relaxamento na assistência da enfermagem. Faz-se necessário sua aplicação com maior ênfase no cotidiano da prática da enfermagem brasileira, como também iniciar a pesquisa para consolidar tais pesquisas.

Consideramos que o uso do relaxamento, como estratégia na intervenção de enfermagem, pode beneficiar os pacientes e os profissionais da enfermagem, promovendo uma forma mais efetiva de enfrentar as situaçöes estressantes, como também prevenção e promoção da saúde.

\section{REFERÊNCIAS BIBLIOGRÁFICAS}

1. AIKEN, L. H.; HENRICHS, T, F. Systematic relaxation as a nursing intervention technique with open heart surgery patients. Nursing Research, v. 20, n. 3, p. 212-217, may.-jun., 1971.

2. AIKEN, L. H. Systematic relaxation to reduce prooperative stress. The Canadian Nurse, p. 38-41, June, 1972.

3. AURIOL, B. Introdução aos métodos de relaxamento. Trad. Marisa Lossano F. Guimarães. São Paulo, Manole, 1985. 135p.

4. BREEDEN, S. A.; KONDO, C. Using biofeedback. American Journal of Nursing, v. 75, n. 11, p. 2010-2012, nov., 1975.

5. CHRISTENSEN, P. J.; KENNEY, J. W. Nursing process: aplication of conceptual models. $4^{a}$. ed. Missouri, Mosby, 1995. 335 p.

6. DOSSEY, B. M. Psychophisiologic self-regulation interventions. In: DOSSEY, B. M.; GUZZETTA, C. E.; KENNER, C. V. Critical care nursing: body-mind-spirit. 3rd., Philadelphia, Lippincott, 1992. Chap.3.

7. FLAHERTY, G. G.; FITZPATRICK, J. J. Relaxation technique to increase comfort level of postoperative patients: a preliminary study. Nursing Research, v. 27, n. 6, p. 352-355, nov.- dec., 1978.

8. GEISSMANN, P.; BOUSINGEN, R. D. Métodos de relaxação. Trad. Helenita Garcez. São Paulo, Loyola, 1987. 262 p. 
9. GIFT, A. G.; MOORE, T.; SOEKEN, K. Relaxation to reduce dyspnea and anxiety in COPD patients, Nursing Research, v. 41, n. 4, p. 242-246, jul./aug., 1992.

10. GUNTHER, B. Sensibilidade e relaxamento: debaixo da sua mente. Trad. Sandor Pethó. $6^{a}$. ed. São Paulo, Brasiliense, 1989. 191 p.

11. HENNINGTHON, S. Exploration of the concept of relaxation. Journal of Holistic Nursing, v. 1, n. 1, p. 21-26

12. HERMAN, J. A. The concept of relaxation. Journal of Holistic Nursing, v.3, n. 1, p. 15-18, 1985.

13. HOLDEN-LUND, C. Effects of relaxation with guided imagery on surgical stress and wound healing. Research in nursing $e$ health, v. 11, n. 4, p.235-244, aug., 1988.

14. KING, I. M. A. A theory for nursing. New "ork: Awiley Medical Publication. 1981. p. 94-112.

15. KOLKMEIER, L. G. Relaxation: open the door to change. In: DOSSEY, B. M. et al. Holistic Nursing: a hand book for practice. United States of America: Aspen, p. 195-220, chap. 11, 1988.

16. LAMONTAGNE, L. L.; MASON, K. R.; HEPWORTH, J. T. Effects of relaxatios on anxiety in children: implications for coping with stress. Nursin Research, v. 34, n. 1, jan./feb., p. 289-292, 1985.

17. LAURA, M. Relaxamento básico: o método fisiológico. São Paulo, Martins Fontes, 1983. 143 p.

18. MADDERS, J. Relax: $o$ alívio da tensão através do controle muscular. Belo Horizonte, Itatiaia, 1978.78 p.

19. REES, B. L. Using relaxation with guided imagery to assist primipara in achieving maternal role attainment. Journal of Holistic Nursing, v. 10, n. 2, p. 167-182, june, 1992.

20. REES, B. L. An exploratory satudy of the effectiveness of a relaxation with guided imagery protocol. Jurnal of Holistic Nursing, v. 11, n. 3, p. 271-276, sep., 1993.

21. REES, B. L. Effect of relaxation with guided imagery on anxiety, depression, and self-esteem in primiparas. Jurnal of Holistic Nursing, v. 13, n. 3 , p. 255-267, sep., 1995.

22. SCHULTZ, I. H. Exercícios de treinamento autógeno: autorelaxamento por concentração. Trad. Hildegard Thiemen Buckup. $21^{2}$. ed. São Paulo, Mande, 1989. 55 p.

23. SMITH, M. J. T.; SELYE, H. Reducing the negative effects of stress. America Journal of Nursing, nov, p. 1953-1955, 1979.

24. STWART, E. To lessen pain: relaxation and rhythmic breathing. America Journal of Nursing, v. 76, n. 6, june, p. 958-959, 1976.

25. THOMPSON, M. B.; COPPENS, N. M.; The effects of guided imagery on anxiety levels and movement of clients undergoing magnetic resonance imaging. Holistic Nurse Practice, v. 8, n. 2, p. 59-69, jan., 1994.

26. TITLEBAUM, H. M. Relaxation. In: Holistic Nursing Pratice. v. 2, n. 3, may., p. 17-25, 1988. 